Virginia Commonwealth University VCU Scholars Compass

1992

\title{
A Comparison of Standard-Dose and High-Dose Epinephrine in Cardiac Arrest outside the Hospital
}

Charles G. Brown

Ohio State University

Daniel R. Martin

Ohio State University

Paul E. Pepe

Baylor College of Medicine

See next page for additional authors

Follow this and additional works at: http://scholarscompass.vcu.edu/emsa_pubs

Part of the Emergency Medicine Commons

From The New England Journal of Medicine, Brown, C. G., Martin, D. R., Pepe, P. E. et al., A Comparison of StandardDose and High-Dose Epinephrine in Cardiac Arrest outside the Hospital, Vol. 327, Page 1051, Copyright (C) 1992 Massachusetts Medical Society. Reprinted with permission.

\section{Downloaded from}

http://scholarscompass.vcu.edu/emsa_pubs/5

This Article is brought to you for free and open access by the Dept. of Emergency Medicine at VCU Scholars Compass. It has been accepted for inclusion in Emergency Medicine Publications by an authorized administrator of VCU Scholars Compass. For more information, please contact libcompass@vcu.edu. 
Authors

Charles G. Brown, Daniel R. Martin, Paul E. Pepe, Harlan Stueven, Richard O. Commins, Edgar Gonzalez, Michael Jastremski, and The Multicenter High-Dose Epinephrine Study Group 


\title{
A COMPARISON OF STANDARD-DOSE AND HIGH-DOSE EPINEPHRINE IN CARDIAC ARREST OUTSIDE THE HOSPITAL
}

\author{
Gharles G. Brown, M.D., Daniel R. Martin, M.D., Paul E. Pepe, M.D., Harlan Stueven, M.D., \\ Richard O. Gummins, M.D., Edgar Gonzalez, Pharm.D., Michael Jastremski, M.D., \\ and the Multigenter High-Dose Epinephrine Study Group*
}

\begin{abstract}
Background. Experimental and uncontrolled clinical evidence suggests that intravenous epinephrine in doses higher than currently recommended may improve outcome after cardiac arrest. We conducted a prospective, multicenter study comparing standard-dose epinephrine with high-dose epinephrine in the management of cardiac arrest outside the hospital.

Methods. Adult patients were enrolled in the study if they remained in ventricular fibrillation, or if they had asystole or electromechanical dissociation, at the time the first drug was to be administered to treat the cardiac arrest. Patients were randomly assigned to receive either $0.02 \mathrm{mg}$ of epinephrine per kilogram of body weight (standard-dose group, 632 patients) or $0.2 \mathrm{mg}$ per kilogram (high-dose group, 648 patients), both given intravenously.
\end{abstract}

Results. In the standard-dose group 190 patients (30 percent) had a return of spontaneous circulation, as

$\mathrm{R}$ ECENT experimental studies of cardiac arrest have demonstrated that, as compared with standard doses of epinephrine $(0.01$ to $0.02 \mathrm{mg}$ per kilogram of body weight), a larger dose $(0.2 \mathrm{mg}$ per kilogram) improves cerebral and myocardial blood flow, the balance between myocardial oxygen supply and demand, and rates of resuscitation. ${ }^{1-7}$ As a result of these investigations, larger doses of epinephrine have been evaluated in several uncontrolled clinical trials. ${ }^{8-12}$ These studies have found improvement in arterial diastolic pressure ${ }^{8}$ coronary perfusion pressure,${ }^{9}$ rates of resuscitation, ${ }^{10}$ and neurologic outcome $^{11,12}$ with high doses of epinephrine.

To compare the efficacy of high-dose epinephrine ( $0.2 \mathrm{mg}$ per kilogram) with that of the standard dose ( $0.02 \mathrm{mg}$ per kilogram) in improving the outcome of resuscitation after out-of-hospital cardiac arrest, we conducted a prospective, randomized, multicenter, double-blind study.

\section{MeThods}

The study protocol was approved by the institutional review board at each of the six participating study centers. Waiver of informed consent was accepted under the guidelines specified in regulation 50.23 of the Food and Drug Administration.

From the Department of Emergency Medicine, Ohio State University, Columbus (C.G.B., D.R.M.); the City of Houston Emergency Medical Services and the Departments of Medicine, Surgery, and Pediatrics, Baylor College of Medicine Houston (P.E.P.); the Department of Emergency Medicine, Medical College of Wisconsin, Milwaukee (H.S.); the Emergency Medicine Services, University of Washington, Seattle (R.O.C.); the Section of Emergency Medical Services, Medical College of Virginia, Richmond (E.G.); and the Program in Multidisciplinary Critical Care, State University of New York Health Sciences Center at Syracuse (M.J.). Address reprint requests to Dr. Brown at the Department of Emergency Medicine, Ohio State University, 108 Means Hall, 1654 Upham Dr., Columbus, $\mathrm{OH} 43210$.

*The members of the Multicenter High-Dose Epinephrine Study Group are listed in the Appendix. compared with 217 patients (33 percent) in the highdose group; 136 patients (22 percent) in the standarddose group and 145 patients (22 percent) in the high-dose group survived to be admitted to the hospital. Twenty-six patients (4 percent) in the standard-dose group and 31 (5 percent) in the high-dose group survived to discharge from the hospital. Ninety-two percent of the patients discharged in the standard-dose group and 94 percent in the high-dose group were conscious at the time of hospital discharge. None of the differences in outcome between the groups were statistically significant.

Conclusions. In this study, we were unable to demonstrate any difference in the overall rate of return of spontaneous circulation, survival to hospital admission, survival to hospital discharge, or neurologic outcome between patients treated with a standard dose of epinephrine and those treated with a high dose. (N Engl J Med 1992;327: 1051-5.)

\section{Patients}

Patients for this study were selected from the populations served by the Emergency Medical Services (EMS) systems of Columbus, Ohio; Houston, Texas; King County, Washington; Milwaukee Wisconsin; Richmond, Virginia; and Syracuse, New York. The study was conducted from October 1, 1989, through December 1, 1990. Patients more than 18 years of age who had cardiopulmonary arrest outside the hospital were eligible for inclusion in the study. A cardiopulmonary arrest was defined as the absence of both spontaneous respiration and palpable pulse. Patients with cardiopulmonary arrest were included in the study if the initial electrocardiographic (ECG) tracing indicated ventricular fibrillation and the patient remained in ventricular fibrillation despite three successive countershocks; if the initial EGG tracing indicated ventricular fibrillation and the ECG rhythm changed to asystole or electromechanical dissociation (defined as any organized ECG complex in the absence of a palpable pulse) after the initial countershocks; or if after basic cardiopulmonary resuscitation (CPR), endotracheal intubation, and the establishment of intravenous access, the initial ECG tracing indicated either asystole or electromechanical dissociation.

Patients who were pregnant or whose cardiopulmonary arrest was associated with trauma, hypothermia, drowning, drug overdose (confirmed by toxicologic analysis), or a primary respiratory arrest (due to upper airway obstruction or hanging, for example) were excluded from the study. Patients were also excluded if an endotracheal tube or intravenous line could not be placed, or if they had clear signs of irreversible cardiac arrest (such as rigor mortis, decomposition, or dependent lividity).

\section{Assignment to Treatment}

Patients were assigned to receive either the standard dose of epinephrine (standard-dose group) or a higher dose of epinephrine (high-dose group) by means of numbered and coded syringes that had previously been placed in random order within packaged groups and then randomly distributed by the manufacturer (Abbott Laboratories, Abbott Park, Ill.) to each study center.

\section{Treatment}

Patients in the two groups were treated according to standard American Heart Association guidelines, ${ }^{13}$ except that the first dose of epinephrine was $0.02 \mathrm{mg}$ per kilogram in the standard-dose 
group and $0.2 \mathrm{mg}$ per kilogram in the high-dose group. To blind the paramedics to the initial dose of epinephrine, precoded, prefilled $20-\mathrm{ml}$ syringes that were identical in appearance were used. The body weights of patients were estimated in pounds, and the dose of epinephrine was administered accordingly, with syringes marked in 10-pound increments (range, 60 to 220). The epinephrine concentration in the syringes used for the standard-dose group was $1: 10,000$, whereas that in the syringes for the high-dose group was 1:1000. Thus, regardless of the study group, equal volumes were administered to patients with the same estimated body weight. The intravenous administration of epinephrine was followed by flushing of the intravenous line with $20 \mathrm{ml}$ of normal saline. ${ }^{14}$ Epinephrine (both standard-dose and high-dose therapy) and all normal saline flushes were given by peripheral intravenous injection. Subsequent therapy followed American Heart Association guidelines. ${ }^{13}$ During the course of the trial all personnel providing care outside the hospital and all study-center investigators remained blinded as to which dose was administered.

\section{Outcome Measures}

The following primary measures of outcome were assessed: return of spontaneous circulation, defined as the return of a palpable pulse and blood pressure (palpable, auditory, or both), without ongoing cardiopulmonary resuscitation, for at least one minute at any time after the administration of the first dose of epinephrine; successful resuscitation, defined as the admission of a patient to the emergency department with a palpable pulse and blood pressure after the return of spontaneous circulation; admission to the hospital, defined as the admission of a patient as an inpatient with a palpable pulse and blood pressure; and discharge from the hospital alive. We also assessed whether patients were conscious at the time of hospital discharge, using a system for grading cerebral performance. ${ }^{15,16}$ The cerebral-performance categories we used were as follows: category 1 , conscious and alert with normal function or only slight disability; category 2 , conscious and alert with moderate disability; category 3 , conscious with severe disability; category 4 , comatose or in a persistent vegetative state; and category 5 , braindead. Each patient's cerebral-performance category at the time of hospital discharge was determined either retrospectively from hospital records or by physical examination.

Specific characteristics of the EMS systems were measured, including the "response interval" and "CPR interval." The response interval was defined as the time from the first telephone call reporting the emergency to the arrival of paramedics at the scene of the cardiac arrest. The CPR interval was defined as the time from the initiation of basic CPR to the initial return of spontaneous circulation. In the case of patients whose cardiopulmonary arrest was witnessed by a bystander, an emergency medical technician, or a paramedic, the "arrest interval" and "epinephrine interval" were also measured. The arrest interval was defined as the time from the onset of cardiopulmonary arrest to the initiation of basic CPR, and the epinephrine interval as the time from the onset of the cardiopulmonary arrest to the administration of epinephrine from the study syringe.

Several prospectively defined variables were recorded immediately after the return of spontaneous circulation; these included hypotension (systolic blood pressure, $<90 \mathrm{~mm} \mathrm{Hg}$ ), hypertension (systolic blood pressure, $\geqslant 200 \mathrm{~mm} \mathrm{Hg}$, or diastolic blood pressure, $\geqslant 120 \mathrm{~mm} \mathrm{Hg}$ ), frequent premature ventricular contractions (more than six per minute), multifocal premature ventricular contractions, and the recurrence of cardiac arrest.

\section{Statistical Analysis}

Means and standard deviations were determined for continuous variables. Percentages were determined for dichotomous variables. Ninety-nine percent confidence intervals were calculated for the differences in the primary outcome measures between the standarddose group and the high-dose group. Ninety-five percent confidence intervals were calculated for the differences between the groups for all other outcome measures. Cerebral performance at hospital discharge was compared by combining patients who were conscious (categories 1, 2, and 3) and combining those who were unconscious (categories 4 and 5). Categorical variables with more than two outcome measures were compared by chi-square analysis or Fisher's exact test. All comparisons were two-tailed. For the primary outcome measure, the results were considered to be statistically significant if the $P$ value was $\leqslant 0.01$ (with Bonferroni's adjustment) ${ }^{17}$ or if the 99 percent confidence interval did not include zero. For all other outcome measures, the results were considered to be statistically significant when the 95 percent confidence interval did not include zero. Subgroup analyses were performed to assess the rates of return of spontaneous circulation, hospital admission, and discharge; the subgroups were stratified according to both the epinephrine interval and the presenting ECG rhythm.

Complications after resuscitation, mortality, and neurologic outcome in the standard-dose and high-dose groups were assessed by a risk-monitoring committee that did not include any of the investigators. The findings of this committee were presented to the institutional review board at Ohio State University College of Medicine and were used to determine whether the risks to the patients in the study remained within acceptable limits.

\section{RESULTS}

\section{Characteristics of the Patients and EMS Systems}

The study population for this investigation was 1280 patients, with 632 randomly assigned to the standard-dose group and 648 to the high-dose group. The characteristics of the patients and the EMS systems were well matched in the two groups (Table 1). The numbers of patients in Tables 1, 2, and 3 do not always equal the total number enrolled because certain data were unavailable for some patients.

\section{Outcome Measures}

The rates of return of spontaneous circulation, successful resuscitation, hospital admission, and survival to hospital discharge were similar between the two groups (Table 2). Ninety-two percent of the patients in the standard-dose group and 94 percent in the highdose group who survived to hospital discharge were conscious at the time of discharge (Table 2).

The average pulse rate at the time of the return of

Table 1. Characteristics of the Patients and EMS Systems.*

\begin{tabular}{|c|c|c|c|c|}
\hline \multirow[t]{2}{*}{ Characteristic } & \multicolumn{2}{|c|}{$\begin{array}{l}\text { STANDaRd-Dose } \\
\text { Group }(\mathbf{N}=632)\end{array}$} & \multicolumn{2}{|c|}{$\begin{array}{l}\text { High-Dose Group } \\
\quad(\mathrm{N}=648)\end{array}$} \\
\hline & VALUE & No. $\dagger$ & VALUE & No.† \\
\hline Age (yr) & $66 \pm 15$ & 628 & $66 \pm 15$ & 647 \\
\hline Male (\%) & 66 & 631 & 67 & 648 \\
\hline $\begin{array}{l}\text { Presenting ECG rhythm (\%) } \\
\text { VF } \\
\text { VT without pulse } \\
\text { Asystole } \\
\text { EMD }\end{array}$ & $\begin{array}{r}49.5 \\
0.5 \\
31.7 \\
18.4\end{array}$ & 631 & $\begin{array}{r}45.1 \\
0.8 \\
33.6 \\
20.5\end{array}$ & 648 \\
\hline CPR by bystander - no. (\%) & $148(24)$ & 631 & $149(23)$ & 646 \\
\hline Response interval (min) & $7.3 \pm 4.2$ & 622 & $7.2 \pm 3.9$ & 640 \\
\hline CPR interval (min) & $22.0 \pm 8.7$ & 178 & $23.3 \pm 12.0$ & 202 \\
\hline $\begin{array}{l}\text { Witnessed cardiopulmonary } \\
\text { arrest }- \text { no. }(\%)\end{array}$ & $248(39)$ & 629 & $233(36)$ & 646 \\
\hline $\begin{array}{l}\text { Arrest interval (min) } \\
\text { Epinephrine interval (min) }\end{array}$ & $\begin{array}{r}4.8 \pm 5.2 \\
17.5 \pm 7.8\end{array}$ & $\begin{array}{l}245 \\
244\end{array}$ & $\begin{array}{r}4.6 \pm 5.1 \\
16.8 \pm 8.2\end{array}$ & $\begin{array}{l}228 \\
230\end{array}$ \\
\hline $\begin{array}{l}\text { Unwitnessed cardiopulmo- } \\
\text { nary arrest — no. (\%) }\end{array}$ & $381(61)$ & 629 & $413(64)$ & 646 \\
\hline
\end{tabular}

*Plus-minus values are means $\pm \mathrm{SD}$. VF denotes ventricular fibrillation, VT ventricular tachycardia, and EMD electromechanical dissociation. Because of rounding, percentages do not always total 100 .

tThe number of patients for whom data were available, specified only for variables with missing data. 
Table 2. Primary Outcome Measures.

\begin{tabular}{|c|c|c|c|}
\hline VARIABLE & $\begin{array}{c}\text { STANDARD-DOSE } \\
\text { GROUP } \\
(\mathrm{N}=632)\end{array}$ & $\begin{array}{l}\text { HIGH-Dose } \\
\text { Group } \\
(\mathrm{N}=648)\end{array}$ & $99 \% \mathrm{Cl}^{*}$ \\
\hline \multicolumn{4}{|c|}{ no. $(\%)$} \\
\hline $\begin{array}{l}\text { Return of spontaneous } \\
\text { circulation }\end{array}$ & $190(30)$ & $217(33)$ & -10 to 3 \\
\hline $\begin{array}{l}\text { Successful } \\
\quad \text { resuscitation }\end{array}$ & $139(22)$ & $147(23)$ & -7 to 5 \\
\hline $\begin{array}{l}\text { Admission to } \\
\text { hospital }\end{array}$ & $136(22)$ & $145(22)$ & -7 to 5 \\
\hline $\begin{array}{l}\text { Discharge from } \\
\text { hospital }\end{array}$ & $26(4)$ & $31(5)$ & -4 to 2 \\
\hline $\begin{array}{l}\text { Conscious at hospital } \\
\text { discharge } \dagger\end{array}$ & $24(92)$ & $29(94)$ & -20 to 16 \\
\hline
\end{tabular}

spontaneous circulation was 109 per minute in the standard-dose group and 115 per minute in the highdose group (95 percent confidence interval for the difference, -14 to 1$)$. Sixty of the 190 patients in the standard-dose group who had a return of spontaneous circulation (32 percent) and 40 of the 217 in the highdose group (18 percent) were categorized as having hypotension when spontaneous circulation returned (95 percent confidence interval for the difference, 5 to 22 percent). Systolic hypertension was observed at the time of the return of spontaneous circulation in 12 patients ( 6 percent) in the standard-dose group and in 32 patients (15 percent) in the high-dose group (95 percent confidence interval for the difference, -14 to -3 percent). Diastolic hypertension was observed almost twice as often in the high-dose group (10 percent) as in the standard-dose group (6 percent) (95 percent confidence interval for the difference, -10 to 1 percent).

The high-dose group had a higher percentage of patients with frequent premature ventricular contractions ( $>6$ per minute), although the percentages of patients with multifocal premature ventricular contractions were similar in the two groups. The percentages of patients in whom cardiac arrest recurred after

Table 3. Outcome Measures in Patients with Return of Spontaneous Circulation.*

\begin{tabular}{lccc}
\hline \hline & $\begin{array}{c}\text { Standard-Dose } \\
\text { Group }\end{array}$ & $\begin{array}{c}\text { High-Dose } \\
\text { Group }\end{array}$ & 95\% Cl ${ }^{\circ}$ \\
Variable & & & \\
$\begin{array}{c}\text { Blood pressure } \\
\text { (mm Hg) }\end{array}$ & & & \\
$\quad$ Auditory systolic & $151 \pm 39$ & $163 \pm 45$ & -29 to 5 \\
Auditory diastolic & $93 \pm 28$ & $103 \pm 31$ & -22 to 2 \\
Palpable systolic & $97 \pm 39$ & $110 \pm 45$ & -24 to -2 \\
$>6$ PVCs/min (\%) & 2 & 7 & -9 to -1 \\
Multifocal PVCs (\%) & 2 & 4 & -5 to 2 \\
Recurrence of & 28 & 33 & -14 to 4 \\
$\quad$ arrest $(\%)$ & & & \\
\hline
\end{tabular}

*Plus-minus values are means \pm SD. PVC denotes premature ventricular contraction.

tThe confidence interval $(\mathrm{Cl})$ for the difference in values between the groups. the return of spontaneous circulation were also similar (Table 3).

The percentages of patients admitted to the hospital who died before discharge (in-hospital mortality) were similar in the two groups $(P=0.98)$. In the first 72 hours, the mortality rate was 42 percent in the standard-dose group and 43 percent in the high-dose group. From 72 to 96 hours after the return of spontaneous circulation, the in-hospital mortality rate was 17 percent in both groups; after 96 hours, it was 41 percent in the standard-dose group and 40 percent in the high-dose group.

Subgroup analyses produced several interesting findings. When high-dose epinephrine was administered within 10 minutes after the onset of cardiac arrest, the rates of survival to hospital discharge were 23 percent in the high-dose group and 11 percent in the standard-dose group (95 percent confidence interval for the difference, -28 to 3 percent). When the groups were stratified according to the presenting ECG rhythm, patients with electromechanical dissociation had higher rates of return of spontaneous circulation when treated with high-dose epinephrine (47 percent) than when they received standard-dose epinephrine (33 percent; 95 percent confidence interval for the difference, -26 to -2 percent).

\section{Discussion}

Our results indicate that in patients who have cardiac arrest outside the hospital, the rates of return of spontaneous circulation, successful resuscitation, hospital admission, and hospital discharge and measures of neurologic outcome were similar after treatment with either standard-dose or high-dose epinephrine. One potential explanation for the discrepancy between the results of experimental studies and those of this clinical trial is that in our study more than 60 percent of the cardiac arrests were not witnessed. Presumably, for most of the patients with unwitnessed arrests, the time from onset to the receipt of epinephrine was prolonged; this length of time may have precluded successful resuscitation. Even for patients whose cardiac arrests were witnessed, the time to the receipt of epinephrine averaged 17 minutes in our study, whereas in the experimental models used to predict clinical dose requirements, this interval was 13 minutes. ${ }^{1,3-7}$ Although some improvement in cerebral and myocardial oxygen delivery may have occurred, the level and duration of oxygen delivery required for successful resuscitation may be greater in humans than in laboratory animals - particularly when ischemia is prolonged. In this study, on the other hand, when epinephrine was administered within 10 minutes of the onset of cardiac arrest, there was a trend toward improved rates of survival to hospital discharge in the high-dose group. Therefore, there may be subgroups of patients who would benefit from higher doses of epinephrine, although further study is needed to evaluate this hypothesis.

In addition, the discrepancy between laboratory 
studies and the results of this clinical trial could be explained by the fact that the majority of patients who die suddenly from cardiac causes have fixed atherosclerotic coronary artery disease. ${ }^{18}$ In such patients, any improvement in myocardial oxygen delivery due to higher doses of epinephrine may be offset by a concomitant increase in myocardial oxygen consumption resulting from the beta ${ }_{1}$-adrenergic effects of epinephrine. ${ }^{19,20}$ In patients with electromechanical dissociation, however, the rate of return of spontaneous circulation was higher when patients were treated with high-dose epinephrine than when they received standard-dose epinephrine. As compared with patients with atherosclerotic coronary disease, in whom ventricular fibrillation is the most common presenting ECG rhythm in cardiac arrest, patients whose presenting ECG rhythm is electromechanical dissociation probably have a lower incidence of coronary artery disease. Therefore, there may be a net metabolic benefit to the myocardium when patients with electromechanical dissociation are treated with high-dose epinephrine rather than with standard-dose therapy. Improved rates of resuscitation in this subgroup of patients have been reported previously. ${ }^{21}$

This study has some limitations. For the majority of patients, we assessed neurologic outcome according to the system of cerebral-performance categories by review of patients' charts. Subtle differences in neurologic outcome may be difficult to detect using this retrospective approach. For this reason, we combined cerebral-performance categories 1 through 3 to identify a subgroup of patients who were conscious at hospital discharge, and categories 4 and 5 to identify a subgroup of patients who were unconscious at discharge. We believe that this information on neurologic status can be obtained accurately without directly examining the patient. For patients who regained consciousness after cardiac arrest, it would have been helpful to assess their degree of independence in activities of daily living. Although obtaining such data would have required more extensive assessment of the patients, it would have made it possible to discern important differences in neurologic outcome after cardiac arrest. Another limitation is that other variables that might have affected neurologic outcome, such as particular therapies given in the hospital, could not be controlled for in this study. Because the number of patients in the two treatment groups who were admitted as inpatients was small, we could not be sure that these confounding variables were equally distributed between the two groups. Furthermore, we did not obtain long-term follow-up data on patients discharged from the hospital. Therefore, neurologic recovery may not have been precisely measured.

In addition, because the rate of survival among patients given standard-dose epinephrine is already quite low, a Type II error is likely. This problem underscores the need to study larger groups of patients in future trials, particularly if subgroups of survivors are to be compared. Finally, although we tried to exclude patients with primary respiratory arrest and those in whom cardiac arrest resulted from a drug overdose, it was difficult to identify such patients accurately even after retrospective review of all available information. We therefore performed an intention-to-treat analysis that included all patients treated with epinephrine at either dose. The results of this analysis did not change our conclusions regarding any of the primary outcome measures.

Although we could not demonstrate any benefit from high-dose epinephrine in this study, we found no adverse effects. One important concern about the use of high doses of epinephrine is the possibility that patients who have already sustained irreversible neurologic injury will be resuscitated. In our study there was no such effect. Another possible complication of high-dose epinephrine is ventricular dysrhythmias occurring after the return of spontaneous circulation. Despite a significantly higher percentage of patients with frequent premature ventricular contractions in the high-dose group, we did not find that a higher percentage of patients in this group had recurrence of cardiac arrest.

In this study, we were unable to demonstrate any difference in the overall rate of return of spontaneous circulation, survival to hospital admission, survival to hospital discharge, or neurologic outcome between patients who received $0.2 \mathrm{mg}$ of epinephrine per kilogram and those who received $0.02 \mathrm{mg}$ per kilogram as the first pharmacologic treatment for out-of-hospital cardiac arrest associated with ventricular fibrillation, asystole, or electromechanical dissociation.

We are indebted to the emergency medical technicians and paramedics serving Columbus, Ohio; Houston, Texas; King County, Washington; Milwaukee, Wisconsin; Richmond, Virginia; and Syracuse, New York; whose dedication and diligence made this study possible; to Lynn Mitchell, M.S., and Melvin Moeschberger, Ph.D., who performed the data analysis and monitored the ongoing results of the trial; and to Abbott Laboratories, which manufactured and supplied the syringes and epinephrine used in this study.

\section{Appendix}

The members of the Multicenter High-Dose Epinephrine Study Group are as follows: D. Keseg, Department of Emergency Medicine, Riverside Hospital, Columbus, Ohio; R.F. Griffith, Department of Emergency Medicine, Ohio State University, Columbus; F. Birinyi, Department of Emergency Medicine, Mount Carmel Medical Center, Columbus; L. Elliot, Department of Emergency Medicine, St. Anthony's Medical Center, Columbus; M. Blue, Department of Emergency Medicine, St. Ann's Hospital, Columbus; R. Thomas and S. Melmed, Department of Emergency Medicine, Grant Hospital, Columbus; L. Bowman, Department of Emergency Medicine, St. Anthony-Mercy Hospital, Columbus; P. Bell, Department of Emergency Medicine, Doctors North Hospital, Columbus; E. Waite, Department of Emergency Medicine, Medical College of Wisconsin, Milwaukee; A. Milewski, Program in Multidisciplinary Critical Care, State University of New York Health Sciences Center at Syracuse; V. Ginger and J. Groom, City of Houston Emergency Medical Services, Houston; J. Graves, Emergency Medicine Services, University of Washington, Seattle; and J.P. Ornato, Division of Cardiology, and E.M. Racht, Section of Emergency Medical Services, Department of Internal Medicine, Medical College of Virginia, Richmond. 


\section{REFERENCES}

1. Brown CG, Werman HA, Davis EA, Hobson J, Hamlin RL. The effects of graded doses of epinephrine on regional myocardial blood flow during cardiopulmonary resuscitation in swine. Circulation 1987;75:491-7.

2. Kosnik JW, Jackson RE, Keats S, Tworek RM, Freeman SB. Dose-related response to centrally administered epinephrine on the change in aortic diastolic pressure during closed-chest massage in dogs. Ann Emerg Med 1985; 14:204-8.

3. Brown CG, Katz SE, Werman HA, Luu T, Davis EA, Hamlin RL. The effect of epinephrine versus methoxamine on regional myocardial blood flow and defibrillation rates following a prolonged cardiorespiratory arrest in a swine model. Am J Emerg Med 1987;5:362-9.

4. Brown CG, Taylor RB, Werman HA, Luu T, Ashton J, Hamlin RL. Myocardial oxygen delivery/consumption during cardiopulmonary resuscitation: a comparison of epinephrine and phenylephrine. Ann Emerg Med 1988;17: 302-8.

5. Brown CG, Birinyi F, Werman HA, Davis EA, Hamlin RL. The comparative effects of epinephrine versus phenylephrine on regional cerebral blood flow during cardiopulmonary resuscitation. Resuscitation 1986;14:171-83.

6. Brown CG, Werman HA, Davis EA, Hamlin R, Hobson J, Ashton JA Comparative effect of graded doses of epinephrine on regional brain blood flow during CPR in a swine model. Ann Emerg Med 1986;15:1138-44.

7. Brown CG, Davis EA, Werman HA, Hamlin RL. Methoxamine versus epinephrine on regional cerebral blood flow during cardiopulmonary resuscitation. Crit Care Med 1987;15:682-6.

8. Gonzalez ER, Omato JP, Garnett AR, Levine RL, Young DS, Racht EM. Dose-dependent vasopressor response to epinephrine during CPR in human beings. Ann Emerg Med 1989;18:920-6.

9. Paradis NA, Martin GB, Rosenberg J, et al. The effect of standard- and high-dose epinephrine on coronary perfusion pressure during prolonged cardiopulmonary resuscitation. JAMA 1991;265:1139-44.
10. Barton $\mathrm{CW}$, Callaham $\mathrm{M}$. High-dose epinephrine significantly improves resuscitation rates in human victims of cardiac arrest. Ann Emerg Med 1990; 19:490-1. abstract.

11. Koscove EM, Paradis NA. Successful resuscitation from cardiac arrest using high-dose epinephrine therapy: report of two cases. JAMA 1988;259: $3031-4$.

12. Goetting MG, Paradis NA. High dose epinephrine in refractory pediatric cardiac arrest. Crit Care Med 1989;17:1258-62.

13. Standards and guidelines for cardiopulmonary resuscitation (CPR) and emergency cardiac care (ECC). JAMA 1986;255:2905-84,

14. Emerman CL, Pinchak AC, Hancock D, Hagen JF. The effect of bolus injection on circulation times during cardiac arrest. Am J Emerg Med 1990; 8:190-3.

15. Brain Resuscitation Clinical Trial I Study Group. Randomized clinical study of thiopental loading in comatose survivors of cardiac arrest. N Engl J Med 1986,314:397-403.

16. Safar $P$. Cerebral resuscitation after cardiac arrest: summaries and suggestions. Am J Emerg Med 1983;2:198-214.

17. Neter J, Wasserman W, Kutner MH. Applied linear statistical models: repression, analysis of variance, and experimental designs. 2nd ed. Homewood, Ill.: Richard D. Irwing, 1985.

18. Kuller LH, Cooper M, Perper J. Epidemiology of sudden death. Arch Intern Med 1972;129:714-9.

19. Livesay JJ, Follette DM, Fey KH, et al. Optimizing myocardial supply/ demand balance of $\alpha$-adrenergic drugs during cardiopulmonary resuscitation. J Thorac Candiovasc Surg 1978;76:244-51.

20. Ditchey RV, Lindenfeld J. Failure of epinephrine to improve the balance between myocardial oxygen supply and demand during closed-chest resuscitation in dogs. Circulation 1988;78:382-9.

21. Lindner KH, Ahnefeld FW, Prengel AW. Comparison of standard and highdose adrenaline in the resuscitation of asystole and electromechanical dissociation. Acta Anaesthesiol Scand 1991;35:253-6.

\section{Massachusetts Medical Society \\ Registry on Continuing Medical Education}

To obtain information on continuing medical education courses in the New England area, call between 9:00 a.m. and 12:00 noon, Monday through Friday, (617) 893-4610 or in Massachusetts 1-800-322-2303, ext. 1342. 